\title{
A Monitoring Policy Framework for the United States Endangered Species Act
}

Megan Evansen ${ }^{1}$, Andrew Carter ${ }^{1}$, and Jacob Malcom ${ }^{1}$

${ }^{1}$ Center for Conservation Innovation

Defenders of Wildlife

Washington, DC 20036

Corresponding author: Megan Evansen

Defenders of Wildlife

Washington, DC 20036

Email address: mevansen@defenders.org 


\begin{abstract}
Biodiversity is deteriorating at a global level as human actions like development, overexploitation, climate change, pollution, and other factors have led to a dramatic increase in the rate of extinction. The U.S. Endangered Species Act is considered one of the strongest laws in the world for protecting wildlife, but its effectiveness depends on proper implementation. Despite the importance of ensuring such proper implementation, the agencies that implement the Act, the U.S. Fish and Wildlife Service (FWS) and the National Marine Fisheries Service (FWS and NMFS; Collectively, the Services) have no systematic monitoring policy to allow such evaluation. This lack of monitoring means the Services cannot accurately evaluate the success of recovery actions, make effective listing, delisting, and downlisting decisions, which can not only put species at risk for further decline, but also result in the misallocation of oftentimes scarce conservation funding. We posit that the absence of a monitoring policy has led to the lack of comprehensive systems to monitor and report on: a) compliance with the law, b) the effectiveness of conservation actions, or c) the state of listed species populations or the status of their threats. To help address this gap, we drafted a monitoring policy that covers (1) biological monitoring; (2) threats monitoring; (3) compliance monitoring; (4) effectiveness monitoring; and (5) investment analysis. The need for increased transparency within and outside the Services; accommodating emerging technologies; and addressing the need for detailed qualitative and quantitative data are considered in this proposal. This blueprint provides a starting point for more detailed monitoring policy and guidance that can help ensure efficient and effective implementation of the ESA and lead to better conservation outcomes for imperiled species.
\end{abstract}


Biodiversity is rapidly deteriorating at a global level as human actions like development, pollution, and overexploitation have led to a dramatic increase in the rate of extinction (IPBES 2019). The U.S. Endangered Species Act ("the Act") is widely considered one of the strongest laws in the world for protecting imperiled species. Part of the law's strength comes from the central role of science: from listing to recovery planning to consultation (Evansen et al. 2020; Malcom and Li 2015; Schwartz 2008), Congress directed that the "best available scientific and commercial data available" be used to make decisions that ultimately determine the fate of species (See critiques of the standard, Doremus 1997). Among other benefits, the use of best available science helps ensure short-term non-biological considerations do not shortchange a species's long-term conservation.

The best available science mandate allows the two services that implement the Act, the U.S. Fish and Wildlife Service and the National Marine Fisheries Service (FWS and NMFS; "Services" collectively), and improve conservation outcomes through adaptive management. In brief, adaptive management both uses and helps generate the best available science. The adaptive management process lays out a cycle of optimization derived from dynamic programming, which includes planning actions; carrying out the actions; monitoring the effects of the action; and then repeating and adjusting plans and actions based on monitoring results (Walters and Hilborn 1978). The integral role that monitoring plays in the adaptive management cycle means that monitoring is essential for the production of the best available scientific data required by the Act.

Though monitoring is intrinsic to adaptive management, the Services have no high-level monitoring policy governing their responsibilities under the Act. Absent a comprehensive monitoring policy, any inclusion of monitoring to improve conservation outcomes (for example, recovery plans under section 4(f) of the ESA) will often be ad hoc, inconsistent and under-prioritized. This results in additional and unnecessary work and difficulties in comparing and consolidating data across larger scales. This lack of effective monitoring means the Services cannot accurately evaluate the effectiveness of recovery actions; make effective listing, delisting, and downlisting decisions; learn about effective mitigation measures across regions or species; and may result in the misallocation of oftentimes scarce conservation funding (Evans et al. 2016). Misallocation of conservation funding means a small number of listed species have received many more times the funding called for in their recovery plan, while other listed species have received far less (Evans et al. 2016). Unsurprisingly, what monitoring data that does exist suggests that while some species may be improving or at least remaining stable, the majority are declining (Evans et al. 2016; Malcom et al. 2016). Indeed, funding for conservation is consistently insufficient, with the FWS receiving less than half of what is required to implement the Act as Congress intended (Malcom et al. 2019). With inadequate resources, it is imperative that the Services implement conservation actions that have a marked effect on moving a species toward recovery. We are missing key information on how actions and plans are affecting conservation outcomes.

Congress did not explicitly designate specific monitoring requirements for threatened or endangered species or critical habitat except in the form of the 5-year status reviews and post-delisting monitoring, stipulated in section 4(g) (U.S. Congress 1973). Yet the need for comprehensive monitoring is recognized by the Service in internal documents that guide the 
implementation of the Act, though this guidance is usually not legally binding (Table 1). Despite this clearly identified need by the Services and Congress, the lack of a direct policy for monitoring means these efforts are not prioritized as other regulatory needs take precedence. Current practice is to assume that conservation agreements such as habitat conservation plans (HCPs) and safe harbor agreements (SHAs) are complied with and effective for species conservation, but there is little monitoring or evaluation of compliance with those agreements (DOI OIG 2008; Owley 2015). Further, programs under other such laws that implicate threatened species and their habitat fall short of fulfillment on paper. The lack of monitoring of programs under the Act means that we cannot know whether there are similar systemic problems that should be addressed. If such problems exist, the species meant to be protected bears the brunt of these errors.

Table 1: Monitoring stipulations found throughout the implementation of the Act.

\begin{tabular}{|c|c|c|}
\hline Where found & Monitoring Focus & Legally Binding? \\
\hline Section $4(\mathrm{~g})$ of the Act & $\begin{array}{l}\text { 5-year reviews on the biological } \\
\text { status and threats of the species }\end{array}$ & Yes - Mandated in text of Act \\
\hline 50 CFR 402.14(i)(3) & $\begin{array}{l}\text { Effects of the action of a section } \\
7(a)(2) \text { consultation }\end{array}$ & Yes - In implementing regulations \\
\hline Section 7 Consultation Handbook & $\begin{array}{l}\text { Monitor for compliance with } \\
\text { consultation requirements (e.g., } \\
\text { impacts on species, conservation } \\
\text { measures, project area limitations) }\end{array}$ & No - Handbook guidance only \\
\hline Recovery Planning Handbook & $\begin{array}{l}\text { Monitor for recovery action } \\
\text { effectiveness }\end{array}$ & No - Handbook guidance only \\
\hline $\begin{array}{l}\text { Habitat Conservation Planning } \\
\text { Handbook }\end{array}$ & $\begin{array}{l}\text { Monitor to evaluate need for } \\
\text { adjustment and adaptive } \\
\text { management }\end{array}$ & No - Handbook guidance only \\
\hline Section $4(\mathrm{~g})$ of the Act & $\begin{array}{l}\text { Monitoring the status of delisted } \\
\text { species for up to } 5 \text { years } \\
\text { post-delisting }\end{array}$ & Yes - Mandated in text of the Act \\
\hline Safe Harbor Agreements (SHAs) & Dependent on individual agreement & Only if in agreement \\
\hline $\begin{array}{l}\text { Candidate Conservation Agreements } \\
\text { with Assurances (CCAAs) }\end{array}$ & Dependent on individual agreement & Only if in agreement \\
\hline
\end{tabular}


We hypothesize that the lack of systematic monitoring under the Act is driven by the lack of a clear legislative, regulatory, or policy direction, in combination with the lack of resources for implementing a rigorous monitoring program. In the nearly 50 years since the passage of the Act, numerous policies have been developed to guide implementation of the various provisions of the Act, including the distinct population segment (DPS) policy (61 FR 4722 (Feb. 7, 1996)), the consultation handbook (USFWS 1998), and recovery planning (NMFS 2010), among others. While some of these policies address the need for monitoring informally, there is no existing structure that guides what should be measured as part of monitoring the implementation of the Act or cements monitoring as a priority. Without such a framework, the Services cannot use knowledge gained through monitoring to assess implementation, leaving the best available science off the table. A concrete monitoring policy framework is thus needed to improve effective conservation of imperiled species under the ESA. Here we introduce ideas for a monitoring policy framework as a starting point for detailed monitoring policy and guidance that can help ensure efficient and effective implementation of the Act and lead to better conservation outcomes for imperiled species.

\section{A Monitoring Policy Framework}

Here we present an initial proposal of a monitoring policy framework under the ESA (SI Appendix A). The purpose of this policy framework is to advance the conservation of listed species by:

1. Establishing a policy to monitor the implementation and effects of the Act.

2. Ensuring that monitoring data are available to make sound conservation decisions.

3. Incorporating the use of adaptive management into implementing the Act.

The monitoring policy framework covers five key areas for reporting: (1) biological status monitoring; (2) threats status monitoring; (3) compliance monitoring; (4) effectiveness monitoring; and (5) investment analysis. Cross-cutting themes, including the need for increased transparency within and outside the Services; accommodating emerging technologies; and addressing the need for qualitative and quantitative data are considered in this framework (Figure $1)$.

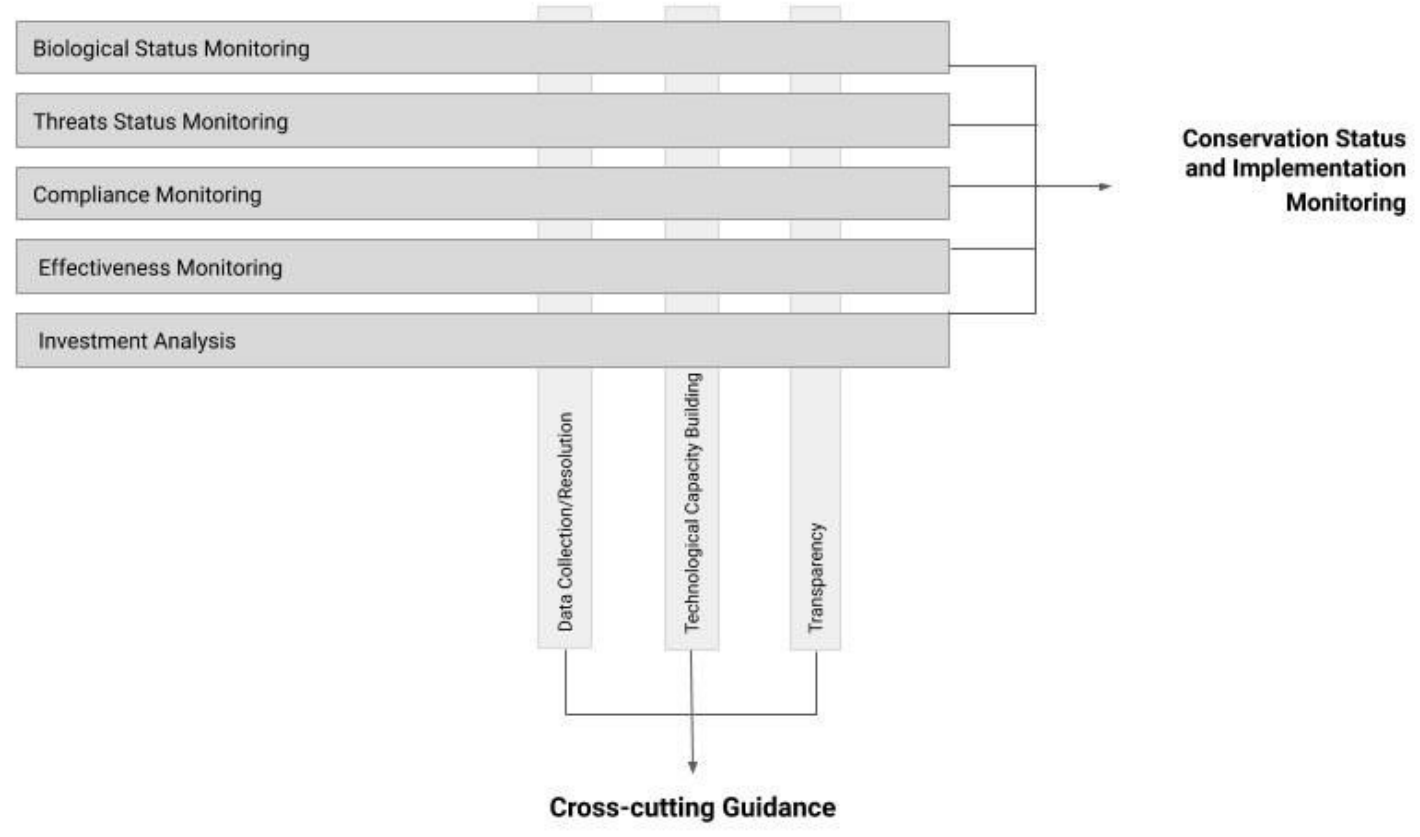


Figure 1: The structure of the monitoring policy framework.

The framework addresses the following core needs:

(a) Incorporation of Adaptive Management. The adaptive management process produces the best available science to be used in the implementation of the Act (Green and Garmestani 2012).

(b) Increased Recovery Effectiveness. Prescribing effective recovery actions is essential for restoring populations. The framework addresses the need to monitor the effectiveness of recovery actions outlined for listed species.

(c) Increased Compliance with the Act. Compliance with permits and agreements is essential for ensuring proper implementation and for assessing where improvements might be made (Malcom et al. 2017).

(d) Consistent Data Collection and Resolution. Improved coordination, collection and resolution of data gathered is incorporated as part of the monitoring process. This includes timely and accurate reporting and the use of standardized measures for qualitative and quantitative data.

(e) Scientific Capacity Building. The timeliness and accuracy of data recorded enables the use of the best available science by decision-makers. The adaptive management process can assess the efficacy of conservation actions prescribed for species' recovery.

(f) Implementation of Cost Effectiveness Analysis. The framework includes a cost-effectiveness analysis of monitoring efforts when the benefits or impacts of a conservation measure are not ones that can be monetized, but rather quantified in the increase in population of a species (Shwiff et al. 2012).

(g) Adoption of Modern Technology. Modern technology can improve monitoring methods; for example, the use of an electronic database that can be updated by staff from any FWS region to enable consistent data recording and facilitate effective conservation.

(h) Increased Transparency. Data transparency to enable agencies, academic researchers, nongovernment organizations and other stakeholders to access the most up-to-date information on imperiled biodiversity facilitates better conservation and decision-making.

(i) Increased Coordination Among All Partners. Coordination with federal, state, local, Tribal, non-governmental and academic partners who share in the responsibility for monitoring species and/or who can assist in the monitoring process will increase the efficiency of monitoring data collection efforts. 


\section{Next Steps}

The final form of a monitoring policy for the Act will require an increase in Service resources, extensive collaboration between the Services and with other government agencies, plus outreach and engagement outside of government (e.g., academics and practitioners). We hope this contribution offers a strong starting point for the process. Until then, a number of step-down actions could both improve current monitoring while at the same time setting the stage for the Services' development of an overarching monitoring policy. The following changes to current monitoring practices would both improve adaptive management processes in the short term, and help with adoption of a monitoring policy in the long term:

1. Improved use of modern technology. Enabling Service biologists to share and access monitoring data through the use of modern databases would improve coordination and transparency among biologists, offices and regions. Incorporating the use of remote imaging technologies will allow for more efficient monitoring. Increasing availability of these data will generally improve the science used for decision-making.

2. Increase funding for monitoring-specific actions. Increasing the funding for monitoring-specific actions allows more resources to be dedicated solely to monitoring efforts, further establishing monitoring a priority. An iterative monitoring process can continuously inform and improve adaptive management, optimize funding allocations, and identify additional funding needs to bring to the attention of policymakers.

3. Dedicated personnel for compliance monitoring. With the addition of a minimum of one additional personnel in each Regional office dedicated solely to compliance monitoring, the Services can increase the capacity for monitoring internally and more effectively coordinate across federal agencies and with other stakeholders. The duties of compliance monitoring personnel can be outlined and prioritized in the policy.

4. Enhanced interagency coordination. The Services can enhance an emerging monitoring program with early, dedicated engagement with federal agencies that share the need to monitor imperiled species. Such coordination is required by sections 7(a)(1) and 7(a)(2) of the Act and can improve access to key monitoring information, increase data collection efficiencies, and highlight knowledge gaps.

5. Coordination with other stakeholders. The Services can maximize capacity and reduce the burden of monitoring by establishing partnerships with those stakeholders for which monitoring efforts are part of their duties. These stakeholders may include but are not limited to: state agencies, Tribes, nongovernmental organizations, regulated entities, and academic partners.

We encourage the Services to move toward the implementation of a comprehensive monitoring policy, starting with initial steps outlined above, to improve the conservation of threatened and endangered species.

\section{Conclusion}

Conserving biodiversity is imperative for the sake of natural systems and people, all of whom depend on functioning ecosystems that biodiversity helps to maintain (IPBES 2019). The Endangered Species Act is the best route to protect imperiled species within the United States, 
but it can only do so if it works as designed. Currently, the lack of a cross-cutting and comprehensive monitoring policy means that despite the strengths of the Act, we cannot determine if it is reaching its full potential. The monitoring policy framework outlined here would fill a major gap in implementing the Act and give rise to using the best available science to improve conservation outcomes for the species that need it most: threatened and endangered plants and animals protected by the Endangered Species Act. 


\section{References}

Congress, U. S. (1973). Endangered species act. US Code, 16, 1534-1544.

Doremus H. (1997). Listing Decisions under the Endangered Species Act: Why better science isn't always better policy. Washington University Law Review 75:1029-1153.

Evansen, M., Li, Y. W., \& Malcom, J. (2020). Same law, diverging practice: Comparative analysis of Endangered Species Act consultations by two federal agencies. PloS one, 15(3), $\mathrm{e} 0230477$.

Evans, D. M., Che-Castaldo, J. P., Crouse, D., Davis, F. W., Epanchin-Niell, R., Flather, C. H., ... \& Male, T. D. (2016). Species recovery in the United States: increasing the effectiveness of the Endangered Species Act. Issues in Ecology.

Intergovernmental Science-Policy Platform on Biodiversity and Ecosystem Services (IPBES). (2019). Summary for policymakers of the global assessment report on biodiversity and ecosystem services of the Intergovernmental Science-Policy Platform on Biodiversity and Ecosystem Services.

https://ipbes.net/sites/default/files/inline/files/ipbes_global_assessment_report_summary_for_pol icymakers.pdf

Green, O.O., \& Garmestani, A.S. (2012). Adaptive management to protect biodiversity: Best available science and the Endangered Species Act. Diversity, 4:164-178.

Malcom, J. W., \& Li, Y. W. (2015). Data contradict common perceptions about a controversial provision of the US Endangered Species Act. Proceedings of the National Academy of Sciences, 112(52), 15844-15849.

Malcom JW, Webber WM, Li Y-W. 2016. A simple, sufficient, and consistent method to score the status of threats and demography of imperiled species. PeerJ 4:e2230. DOI:

10.7717/peerj.2230.

Malcom, J., Kim, T., \& Li, Y. W. (2017). Free Aerial Imagery as a Resource to Monitor Compliance with the Endangered Species Act. BioRxiv, 204750.

Malcom, J., \& Evansen, M. (2019). Funding needs for the U.S. Fish and Wildlife Service endangered species program, FY 2020. Center for Conservation Innovation, Defenders of Wildlife.

National Marine Fisheries Service ([NMFS)]. National Marine Fisheries Service. (2010). Interim Endangered and Threatened Species Recovery Planning Guidance, version 1.3. NMFS.

Owley J. 2015. Keeping Track of Conservation. Ecology Law Quarterly 42:79-138. 
Schwartz, Mark W. (2008). The performance of the Endangered Species Act. Annu. Rev. Ecol. Evol. Syst. 2008, 39:279-99.

Shwiff SA, Anderson A, Cullen R, White PCL, Shwiff SS. (2012). Assignment of measurable costs and benefits to wildlife conservation projects. Wildlife Research 40:134-141.

U.S. Dept. of the Interior Office of the Inspector General (DOI OIG). (2008). Program assessment rating tool progress evaluation: U.S. Fish and Wildlife Service Endangered Species Program. No. Y-RR-FWS-0007-2007.

U.S. Fish and Wildlife Service (FWS). (1998). Procedures for Conducting Consultation and Conference Activities Under Section 7 of the Endangered Species Act.

Walters, Carl. J. \& Hilborn, Ray. (1978). Ecological optimization and adaptive management. Ann. Rev. Ecol. Syst. 1978, 9:157-88. 


\section{SI Appendix A}

There is no policy under the U.S. Endangered Species Act to guide monitoring species, habitats, and threats. Without such a framework, the Services cannot use knowledge gained through monitoring to assess implementation, leaving the best available science off the table. A concrete monitoring policy framework is thus needed to improve effective conservation of imperiled species under the ESA. The following is a draft proposal for a framework for such a policy.

\section{Framework}

In furtherance of this policy and its associated goals as outlined above, the Services shall develop monitoring plans and processes that meet the requirements set forth below:

1. Conservation status

a. Biological Monitoring

i. Monitor factors intrinsic to listed species, which may include, in order of general importance: population size; population numbers; age or stage structure; genetic diversity; and any others that the Secretary deems necessary to improve the adaptive management of threatened or endangered species.

ii. Monitor the extrinsic factors of the biological status of listed species, which may include, in order of general importance: the quantity of habitat; the quality of habitat; the spatial and temporal distribution of habitat across a species current or potential range; and any other factors extrinsic to a species that the Secretary deems necessary to improve the adaptive management of threatened or endangered species.

iii. Monitor species at-risk for imminent listing under the ESA, particularly those that fall within project/permit action areas (e.g., section 7 consultations or section 10 habitat conservation plans). Any at-risk species potentially harmed by approved actions should be included in monitoring reports submitted back to the Services by federal agencies, and the Services should suggest avoidance and mitigation actions to help avoid a future listing.

iv. Monitor species delisted from the Act due to recovery, as per section 4(g).

v. Monitor species delisted from the Act due to presumed extinction, for no less than 5 years post-delisting or at a timescale appropriate for the biology of the species.

vi. Establish and/or expand agreements between federal agencies, and between those agencies and other parties with responsibility for monitoring of imperilled species. Such agreements should comprehensively address questions of resource sharing and set forth division of authorities. 


\section{b. Threats Status Monitoring}

i. Monitor the status of all threats to listed species as laid out in ESA documents and report on the status of the threats (into the foreseeable future ${ }^{1}$ ) at a timeline and at intervals that correspond to the timescale of the threat until such a time as: the species is no longer listed, or: until such a time as the threats have been determined to be abated, or; for the duration of the listing under the ESA. These threats may include but are not limited to: climate change; habitat destruction and modification; disease; overutilization; and invasive species.

ii. Monitor the status of all threats as laid out in ESA documents after species recovery at a timeline and at intervals that correspond to the timescale of the threat to prevent a relapse in listing need.

2. Implementation

a. Compliance Monitoring

i. Monitor compliance of actions carried out for listed species by the States as part of agreements under ESA section 6.

ii. Monitor compliance with the terms and conditions of actions authorized through ESA sections 7.

iii. Monitor violations of the take prohibitions of ESA section 9.

iv. Monitor compliance with the terms and conditions of all conservation agreements authorized under ESA section 10.

v. Monitor the extent and intensity of actions affecting listed species but not authorized by the Services. Expanding partnerships with non-federal institutions that participate in the monitoring of imperiled species (Scott et al. 2010).

vi. Place the greatest emphasis for monitoring compliance on actions that have the greatest impact on listed species or their critical habitat.

vii. Have no less than one individual staff person in each region to focus solely on the issue of compliance monitoring and provide regular training for personnel to remain up-to-date on emerging technology and data collection methods.

b. Effectiveness Monitoring

i. Monitor the effectiveness of conservation actions designed to avoid, minimize, and mitigate harm to threatened species and endangered species as designated during the implementation of sections 7 and 10 of the Act.

ii. Action proponents (agencies, grantees, or permittees) shall be required to deliver monitoring reports of approved actions back to the Services as laid out by the Services in all handbooks pertaining to that section.

iii. Monitor the effectiveness of carrying out recovery actions detailed in the most recent final or draft recovery plan for a listed species, or actions aimed at conserving species without recovery plans. Monitor at a timeline and at intervals that correspond to the timescale of the recovery action

\footnotetext{
${ }^{1}$ We use the definition of foreseeable future as presented in the new regulations issued in 2019 (84 FR 45020 (Aug.
} 27, 2019), and found in 50 CFR $\S 424.11(d)$. 
until: the recovery of the species is no longer deemed dependent on the recovery action; or the species has recovered.

iv. Mitigation efforts shall be monitored for their effectiveness at reducing or offsetting the impact of the proposed action on the species.

c. Investment Analysis

i. Investment Monitoring. Monitor all investments in monitoring actions in order to track the biological outcome of said monitoring investments.

1. Record all investment data in an online database and regularly update the data to allow for monitoring of investments through time.

ii. Cost-effectiveness. Ensure that any monitoring program arising from this policy shall include, at a minimum, a non-quantitative cost-effectiveness analysis of conservation actions, as conservation outcomes are frequently not ones that can be quantified in economic terms (Shwiff et al. 2012).

3. Cross-cutting Guidance

a. Data Collection and Resolution

i. Guidelines. Set rigorous guidelines for data collection, including:

1. Recording all qualitative monitoring data and adhering to standardized guidelines to maximize consistency and increase the ability for data sharing.

2. Maintaining detailed quantitative data records that adhere to guidelines that are consistent between Regions.

b. Technological Capacity Building.

i. Cost efficiency. Improve the cost efficiency of carrying out conservation actions and allowing for more accessible data sharing within and between agencies.

ii. Best Available Science. Facilitate the use of the best available science, improve accuracy and reliability, and keep important data up to date by incorporating updated technology platforms into standard procedures.

iii. Technology use. Use established and emerging technologies, including software, firmware, and hardware to maximize the cost effectiveness of monitoring, where:

1. Software may include but is not limited to databases, GIS and spatial analysis software, statistical software, web-based communications tools, web applications, and other software as the Services deem appropriate;

2. Firmware may include but is not limited to: read-only software embedded in: wildlife monitoring devices, drones for collecting data, networking components, and vehicles.

3. Hardware may include but is not limited to: drones for collecting data, remote sensing technology, devices intended to monitor wildlife in the field (e.g. tracking collars or wildlife cameras), and technology developed to measure biological, chemical, or physical parameters in the field, etc. 
iv. Technology Adoption. Adoption of new technology will be subject to a balancing test that considers the benefits from use of that technology in terms of:

1. The direct costs of a technology, including those costs associated with training, considered in light of its benefits.

2. The cost of scaling the technology as needed.

3. The longevity of the technology for the agency.

v. Innovative Culture. Facilitate this work by supporting a culture of innovation and communities of practice.

c. Transparency.

i. Public Availability of Data. Allow monitoring data to be easily publicly available (to the maximum extent practicable) as information sharing reduces transaction costs for all players in a system and allows for access to the most complete and updated data.

ii. Exceptions. Allow for the limiting of access to monitoring data in cases where:

1. There is concrete evidence that releasing detailed monitoring data will compromise a species' conservation.

2. Releasing the data will reveal otherwise protected data.

3. The cost of releasing the data exceeds the direct and indirect benefits.

4. Any other reason as deemed prudent by the Secretary so long as it is consistent with the purposes of the Endangered Species Act.

4. Relationship to Other Activities.

a. Codes and Conduct. This policy will be subject to the appropriate codes of professional and scientific conduct applicable to each service, including but not limited to:

i. the Department of Interior's uniform code of professional conduct (305 DM 3)

ii. the Fish and Wildlife Service's supplement to that code (212 FW 7), and

iii. the National Oceanic and Atmospheric Administration's Administrative Order concerning Scientific Integrity (202-735D) as well as the Fish and Wildlife Service's Scientific Integrity Act (H. R. 1709), which outlines certain scientific integrity policies for Federal agencies that fund, conduct, or oversee scientific research. 
b. OPEN Government Data Act. This policy framework and any actions undertaken pursuant to it are intended to be consistent with all existing requirements of the OPEN Government Data Act, Pub. L. No. 115-435, tit. II (2019), which requires federal agencies to collect or create information in a way that supports downstream information processing and dissemination activities, and requires the publication of their information online as open data using standardized, machine-readable data formats.

c. OSTP Guidance. This policy is also subject to all Office of Science and Technology Policy (OSTP) guidance.

d. Environmental Justice. This policy framework and any actions undertaken pursuant to it should be implemented so as to support environmental justice, in conformity with Executive Order 12898 (Feb. 11, 1994), and as appropriate the requirements of the U.S. Department of the Interior's Environmental Justice Strategic Plan. This shall include, but is not limited to:

i. Evaluation of the impacts of any monitoring activities on the geographic area, taking into consideration both direct and indirect effects.

ii. Effects of monitoring activities on any impacted communities in the area where monitoring will occur.

iii. Evaluation of any underlying effects from the action being monitored (including HCPs, recovery plans, or other agency actions) on impacted communities.

iv. Incorporation of monitoring data into environmental justice analyses made in conjunction with habitat conservation plans, recovery plans, environmental impact assessments, or other relevant agency actions.

v. Equitable access to monitoring programs and data in order to give impacted communities the tools and information they may need for public participation in conservation actions carried out by agencies.

vi. At minimum, an informal consultation with relevant Tribal Nations to ensure all monitoring efforts comply with conservation agreements established between Native communities and federal agencies. 